\title{
Agreeableness and Conscientiousness as Antecedents of Deviant Behavior in Workplace
}

\author{
Farhadi, H. ${ }^{1}$, Fatimah, O. ${ }^{1}$, Nasir, R. ${ }^{1} \&$ Wan Shahrazad, W. S. ${ }^{1}$ \\ ${ }^{1}$ School of Psychology and Human Development, Faculty of Social Sciences and Humanities, Universiti \\ Kebangsaan Malaysia, Bangi, Selangor, Malaysia \\ Correspondence: Fatimah, O., School of Psychology and Human Development, Faculty of Social Sciences and \\ Humanities, Universiti Kebangsaan Malaysia, 43600 UKM Bangi, Selangor, Malaysia. Tel: 60-3-8921-3628. \\ E-mail: faas@ukm.my
}

Received: June 4, 2012

Accepted: June 16, 2012 Published: July 16, 2012

doi:10.5539/ass.v8n9p2

URL: http://dx.doi.org/10.5539/ass.v8n9p2

\begin{abstract}
In recent years, there has been an increase in the interest of workplace deviant behavior (WDB) among industrial and organizational psychologists. Many scholars believe that WDB decreases overall organizational productivity. The main purpose of this study was to investigate the relationship of both agreeableness and conscientiousness (two factors of big five model of personality traits) with deviant behavior. The study also looked at the role of two demographic factors (gender and age) on deviant behavior in workplace. Data were collected from 212 subjects who were working as civil servants in Malaysia using a set of questionnaire that measures the variables studied. The results showed that personality traits predicted workplace deviant behavior. There were negative relationships between agreeableness and conscientiousness with workplace deviance. Although the findings of the present study showed differences in WDB between subjects with different age levels, it was unable to find differences in WDB between subjects with different gender. Implications for future research are discussed.
\end{abstract}

Keywords: workplace deviance, agreeableness, conscientiousness, demographic factors, industrial and organizational psychology

\section{Introduction}

Workplace deviant behavior (WDB) is an important topic for organizational researchers and practitioners because of its increasing occurrence and potential consequences (Spector and Fox, 2005). In recent years, it has also generated high interest among industrial organizational psychologists because of its pervasiveness in organizations. Billions of dollars were lost each year as a result of workplace deviance. The prevalence of workplace deviance is therefore costly to both organizations and individuals (Bennett and Robinson, 2003). When employees engage in workplace deviant behavior, these behaviors can have detrimental effects on the organizations. For instance, organizations lost up to $\$ 200$ billion dollars per year from employee theft, $\$ 4.2$ billion for violence, and $\$ 5.3$ billion for employees' recreational web surfing (Greenberg, 1997).

Employees who are targets of deviance may experience more turnover, damaged self-esteem, increased insecurity at work, also psychological and physical pain. Therefore, the discussion above illustrated that the impact of these behaviors are important and serious thus need to be investigated by organizational researchers (Bennett and Robinson, 2003). However, a large proportion of research on behavior at work has focused on desirable behaviors such as organizational citizenship or prosaically behaviors (Robinson and Bennett, 1995). A large number of empirical studies done to date have focused on causes or predictors of workplace deviance, some of them have examined potential antecedents of workplace deviance (Omar et al., 2011). Although, much of the past research that examines predictors of workplace deviance has focused on situational factors (job stress, job satisfaction, organizational justice) investigating the personal factors such as personality traits as predictors of WDB is also important (Farhadi et al., 2011).

Based on the potential antecedents of deviant behavior, Bennett and Robinson (2003) conceptualized deviant behavior as a reflection of individual personality. They believed that deviant behavior as a reflection of personality refers to predicting negative behavior from stable individual differences. Also, theory of planned behavior (Ajzen, 1991) stated that individual differences can be used to explain the function of behavior which influences the occurrence of deviant behavior in workplace (Cullen and Sackett, 2003). According to mentioned 
theory (e.g., XXX), personality can influence the occurrence of deviant behavior. Specifically, personality can influence the belief components associated with the attitude towards a given negative behavior.

Despite numerous studies in this area that have been carried out in Western countries, only a few have been conducted in Asian countries particularly, Malaysia. The study reported in this paper was conducted with Malaysian samples to explore the relationship of personality traits and WDB in a non-Western society with its own specific culture. In particular, the current study have focused on agreeableness and conscientiousness, two factors of big five model of personality traits, as predictors of WDB. We also examined the differences of two demographic factors (gender and age) among subjects on engaging in deviant behavior.

\subsection{Conscientiousness and Workplace Deviant Behavior}

Many researchers have stated that among the Big Five, conscientiousness most effectively predicts a variety of criteria in the workplace. Conscientiousness plays an important and central role in determining performance levels at work (Vardi and Weitz, 2004). Therefore, it must be taken into consideration when attempting to predict and explain factors related to such criterion in workplace (Vardi and Weitz, 2004).

Conscientiousness, which is the third trait in the Five Factor Model of personality, is described by traits such as trustworthiness, competence, achievement striving, responsibility, self-discipline, dutifulness and efficiency (Costa and McCrae, 1992; Goldberg, 1990). People who score high on this dimension are regarded as well organized, good planners, and achievement oriented (Vardi and Weitz, 2004). In addition, conscientious individuals report higher grade point average, greater job satisfaction, greater job security, and more positive as well as committed in social relationship.

On the other hand, some prior studies have shown conscientiousness is negatively related to deviant behavior in organizations (Farhadi et al., 2011; Berry et al., 2007; Dalal, 2005; Salgado, 2002). For example, Farhadi et al. (2011) carried out a pilot research on 162 employee of an organization to examine the predictor role of conscientiousness on workplace deviance. They found a negative relationship between conscientiousness and workplace deviant behavior. A study carried out by Bowling and Nathman (2010) showed that there was negative relationship between conscientiousness and counterproductive work behavior (the correlation between conscientiousness and CWBs was -0.35).

Furthermore, Barrick and Mount (1991) and Judge et al. (1997) showed that there is a negative relationship between turnover and absenteeism (a type of WDB) with conscientiousness, respectively. Thus, based on the aforementioned studies, the current study aims to extend the literature by further investigating the relationship between conscientiousness and WDB. Therefore, the following hypothesis is suggested:

Hypothesis1: There is a negative significant relationship between conscientiousness and workplace deviant behavior.

\subsection{Agreeableness and Workplace Deviant Behavior}

Agreeable individuals are described as pleasant, tolerant, helpful, trusting, forgiving, considerate, and they tend to be cooperative (Bowling and Eschleman, 2010). Graziano and Eisenberg (1997) found that employees ranked high on agreeableness are more likely to display less hostility and aggression toward others during work time. Likewise, Mount et al. (2006) found that agreeableness had a direct negative relationship with interpersonal counterproductive behaviors and job satisfaction partially mediated the relationship between agreeableness and workplace deviance. In addition, three meta-analytic results have shown agreeableness trait is negatively related to negative behavior in organizations (Berry et al., 2007; Dalal, 2005; Salgado, 2002). Consequently, the current study aims to extend the literature by further investigating the relationship between agreeableness and WDB. Therefore, the following hypothesis is suggested:

Hypothesis 2: There is a negative significant relationship between agreeableness and workplace deviant behavior.

\subsection{Demographic Variables and Workplace Deviant Behavior}

With regard to demographics factors with workplace deviant behavior, findings have been inconsistent. Some findings found differences in workplace deviant behavior between employees with different demographic background, whereas some studies could not find any differences. One study indicated that gender were more strong predictors of interpersonal aggression (Hershcovis et al., 2007). Gender and age were found to be related to workplace deviant behavior while tenure was not. A meta-analysis done to review antecedent of deviant behavior in organization found that age, sex and marital status were all valid predictors of different deviant behavior with age as the most powerful predictor of deviant behavior (Lau and Sholihin, 2005). Thus the current study intends to investigate the difference in workplace deviant behavior among subjects with different gender and age level. Two hypotheses were developed and they are: 
Hypothesis3: There is a significant difference in workplace deviant behavior among male and female subjects.

Hypothesis4: There is a significant difference in workplace deviant behavior among subjects with different age level.

\section{Method}

\subsection{Research Design}

This study used a non-experimental quantitative research design. A set of questionnaire was used at a single point of time. The present study was designed to examine the existing relationship between agreeableness and conscientiousness as independent variables with workplace deviant behavior as dependent variable. This exploratory study was used to determine and describe the degree of relationship between dependent and independent variables in descriptive and quantitative terms.

\subsection{Participants and Procedure}

This study was conducted in a public organization in Malaysia. The participants in this study were 212 civil servants who were selected randomly from an organization in Malaysia. To decrease bias in sampling, a random sampling method was used. The sample consisted of 93 males and 119 females ranging in age from 18 to 65 years.

\subsection{Instruments}

A set of questionnaire that consists of four sections was used to measure the study variables and they are:

Workplace Deviant Behavior measurement: Employee deviant behavior was measured using Bennett and Robinson's (2000) Workplace Deviance Scale. This19-item measure with a 7-point Likert-type response scale was used to measure the extent to which participants have engaged in workplace deviance during the past year. Item responses ranged from $1=$ never, $2=$ once a year, $3=$ twice a year, $4=$ several times a year, $5=$ monthly, 6=weekly, and 7=daily. Examples of the workplace deviance items included: "Played a mean trick on someone at work", "Made fun of someone at work", "Cursed at someone at work". Cronbach's alpha for the 19 workplace deviance items was $\alpha=0.91$.

Personality traits measurement: This construct was measured using a set of Mini-Markers developed by Saucier (1994). This 16-item measure with a 9-point Likert-type response scale was used to measure the agreeableness and conscientiousness. Item responses ranged from $1=$ extremely inaccurate, $2=$ very inaccurate, $3=$ moderately inaccurate, $4=$ slightly inaccurate, $5=$ ?, $6=$ slightly accurate, $7=$ moderately accurate, $8=$ very accurate, and $9=$ extremely accurate. The Cronbach's alpha for the 16-items was $\alpha=0.85$.

Demographic Questions: Two demographic items were included in the survey. Items assessed participants' gender and age level.

\subsection{Statistical Analysis}

The data were analyzed using Statistical Package for the Social Sciences (SPSS). The data file was uploaded into SPSS 16, and the variables were categorized as nominal, ordinal or scale as appropriate. In addition, the variables were labeled appropriately to make the SPSS output easier to interpret. Reliability coefficients were computed for main variables. This study utilized such technique as descriptive statistics, Cronbach's alpha, Pearson's correlational analysis, one way ANOVA and independent sample t-test to investigate the relationships between the independent and dependent variables.

\section{Results and Discussions}

Descriptive and zero-order correlations are presented in Table 1. As shown, there were negative and strong relationships between two factors of personality traits (agreeableness and conscientiousness) with workplace deviant behavior. A Pearson correlation coefficient will be utilized to test hypothesis 1 that states that there is a negative significant relationship between conscientiousness and workplace deviant behavior.

Table 1. Means, standard deviation and correlations among observed variables

\begin{tabular}{llllll}
\hline Variable & Mean & SD & 1 & 2 & 3 \\
\hline WDB (1) & 36.90 & 17.10 & & & \\
Agreeableness (2) & 41.40 & 5.70 & $-0.36^{*}$ & 0.85 & \\
Conscientiousness (3) & 39.10 & 6.60 & $-0.36^{*}$ & $0.57^{*}$ & 0.85 \\
\hline
\end{tabular}

${ }^{*} \mathrm{p}<0.01$ 
Results from the analysis (refer Table 1) showed that there is a negative significant relationship between workplace deviant behavior and conscientiousness $(r=-0.36, p<0.01)$. This means that the lower the conscientiousness reported by the subjects, the higher the tendency for them to be involved in workplace deviant behavior. Thus hypothesis 1 was supported.

Conscientious individuals tend to be good corporate citizens and invest exceptional effort at work without expecting rewards. Also, according to Goldberg (1990), the key adjective markers of the conscientiousness are: organized, neat, orderly, practical, and prompt. Thus, as shown in the present study it was possible to conclude that those who are low on conscientiousness do not perform well at work and may be more disposed to engage in a variety of behaviors that may be deviant or even harmful to the organization or members in organizations.

With regard to agreeableness, the second hypothesis predicted a negative relationship between agreeableness and workplace deviant behavior, such that participants higher in agreeableness would be less likely to engage in workplace deviant behavior. The results of the present study were able to support this hypothesis (see Table1). Significant negative relationship was found between participants' levels of agreeableness and their reported levels of WDB. This finding is consistent with Mount et al. (2006), Salgado (2002), and Graziano and Eisenberg (1997), who agreed there is a negative relationship between agreeableness and deviant behavior.

This consistency can be explained by several reasons: first, agreeable individuals are described as pleasant, tolerant, helpful, trusting, forgiving, considerate, and they tend to be cooperative (Bowling et al., 2010). In addition, previous research showed a clear negative relationship between deviant behavior and positive behavior in organizations [e.g., Dalal, 2005; Bennett and Robinson, 2000). Therefore, based on the previous research it can be reasonable existing significant negative relationships between agreeableness and WDB.

The third hypothesis states that there is a significant difference on workplace deviant behavior among samples with different gender. Independent sample t-test was used to compare the WDB for women and men samples (see Table 2). This present study found that there was no significant differences between the WDB scores among women and men $(t=-0.34, p>0.05)$. Therefore, this present study was unable to support hypothesis 3 .

Table 2. Independent sample t-test for comparing the women and men's WDB scores

\begin{tabular}{lllllll}
\hline Variable & & $\mathrm{N}$ & Mean & $\mathrm{SD}$ & $\mathrm{df}$ & $\mathrm{t}$ \\
\hline Overall WDB & Male & 93 & 1.92 & 0.92 & 210 & -0.34 \\
& Female & 119 & 1.97 & 0.89 & &
\end{tabular}

From Table 2 , it can be seen that there is no difference in the mean between the two groups which means that for both male and female subjects, the occurrence of deviant behavior among them are the same. This finding does not support previous findings (Hershcovis et al., 2007; Henle, 2005), whereby in their findings they found that gender can predict and is related to negative behavior in workplace.

One-way ANOVA analysis was used to test whether there was any difference between subjects with different age categories in workplace deviance behavior in hypothesis 4 . Based on the analysis shown in Table 3, there was a significant difference in WDB between samples with different age levels $(\mathrm{F}=3.6, \mathrm{p}<0.01)$. Therefore, based on this finding, the present study was able to support hypothesis 4. (refer Table 3).

Table 3. One way analyses of variance (ANOVA) for comparing the WDB with different age level

\begin{tabular}{lllll}
\hline Source & SS & df & MS & F \\
\hline Between groups & 11.20 & 4 & 2.80 & $3.60^{*}$ \\
Within groups & 159.70 & 207 & 0.772 & \\
Total & 171 & 211 & &
\end{tabular}

On the whole, despite the differences in cultures, nationalities, values, attitudes, economic and political background in Malaysia, the findings of the present study support the research done in other Western countries. Correlational analyses identified significant negative relationships between conscientiousness and agreeableness with WDB. This study found significant result in deviant behavior among sample with different age level. However, it did not found significant result between gender differences. The present study provides evidence that WDB be influenced by personality traits. The result of the present study is in line with previous empirical research on the relationship between personality traits and WDB. 


\section{Conclusion}

In conclusion, consistent with the previous research this study found that conscientiousness and agreeableness yielded significant relationships with workplace deviance behavior. It means that employees with less conscientiousness and agreeableness characteristic engage in deviant behavior more often than their more conscientious and agreeable counterparts. In general, the present study considers personality traits would contribute to predict deviant behavior in workplace. Findings of the present study demonstrate that the issues associated with WDB and personalities in Asian culture, particularly Malaysia, were mostly in line with previous studies in Western society.

For future research on WDB, we would highly suggest that the researches are to be done in a large number of respondents. Like any other organizational behaviors, WDB is best seen when performed collectively which will contribute highly to the validity of the data. In addition, more research is needed to examine the relationship between other personality traits such as extraversion, and emotional stability with workplace deviant behavior. Also, it is suggested that future researchers to consider both situational and personal factors in their studies as predictors of negative behavior in organizations.

\section{References}

Ajzen, I. (1991). Theory of planned behaviour. Organizational Behaviour and Human Decision Processes, 50(2), 179-211. http://dx.doi.org/10.1016/0749-5978(91)90020-T

Barrick, M. R., \& Mount, M. K. (1991). The big five personality dimensions and job performance: A meta-analysis. Personnel Psychology, 44(1), 1-26. http://dx.doi.org/10.1111/j.1744-6570.1991.tb00688.x

Bennett, R. J., \& Robinson, S. L. (2000). Development of a measure of workplace deviance. Journal of Applied Psychology, 85(3), 349-360. http://dx.doi.org/10.1037/0021-9010.85.3.349

Bennett, R. J., \& Robinson, S. L. (2003). The past, present and future of workplace deviance research. In J.Greenberg (Ed.), Organizational behaviour: The state of the science (2nd ed.) (pp. 247-281). Mahwah, NJ: Erlbaum.

Berry, C. M., Ones, D. S., \& Sackett, P. R. (2007). Interpersonal deviance, organizational deviance, and their common correlates: A review and meta-analysis. Journal of Applied Psychology, 92(2), 410-424. http://dx.doi.org/10.1037/0021-9010.92.2.410

Bowling, Nathan. A. (2010). Effects of job satisfaction and conscientiousness on extra-role behaviours. Journal of Business and Psychology, 25(1), 119-130. http://dx.doi.org/10.1007/s10869-009-9134-0

Bowling, Nathan. A., \& Eschleman, Kevin J. (2010). Employee personality as a moderator of the relationships between work stressors and counterproductive work behaviour. Journal of Occupational Health Psychology, 15(1), 91-103. http://dx.doi.org/10.1037/a0017326

Costa, P. T., \& McCrae, R. (1992). Revised NEO Personality Inventory (NEO-PI-R) and NEO Five-Factor Inventory (NEO-EEI) professional manual. Odessa, FL: Psychological Assessment Resources.

Cullen, M. J., \& Sackett, P. R. (2003). Personality and counterproductive workplace behaviour. In M.R. Barrick \& A.M. Ryan (Eds.), Personality and work: Reconsidering the role of personality in organizations (pp.150-182). San Francisco: John Wiley \& Sons.

Dalal, R. S. (2005). A meta-analysis of the relationship between organizational citizenship behaviour and counterproductive work behaviour. Journal of Applied Psychology, 90(6), 1241-1255. http://dx.doi.org/10.1037/0021-9010.90.6.1241

Farhadi, H., Omar, F., Barazandeh, A., \& Farhadi, S. (2011). The Role of conscientiousness as an antecedent of workplace deviant behaviour. Procedia-Social and Behavioural Science Journal.

Goldberg, L. R. (1990). An alternative 'description of personality': The Big Five factor structure. Journal of Personality and Social Psychology, 59(6), 1216-1229. http://dx.doi.org/10.1037/0022-3514.59.6.1216

Graziano, W. G., \& Eisenberg, N. (1997). Agreeableness: A dimension of personality. In R. Hogan, J. Johnson, \& S. R. Brrigs (Eds.), Handbook of personality psychology (pp. 795-824). San Diego, CA: Academic Press.

Greenberg, J. (1997). Antisocial behaviour in organizations. Thousand Oaks, CA: Sage.

Henle, C. A. (2005). Predicting workplace deviance from the interaction between organizational justice and personality. Journal of Managerial Issues, 17(2), 247-263. 
Hershcovis, S. M., Turner, N., Barling, J., Arnold, K. A., Dupre, K. E., Inness, M., LeBlanc, M. M., \& Sivanathan. (2007). Predicting workplace aggression: A meta-analysis. Journal of Applied Psychology, 92(1), 228-238. http://dx.doi.org/10.1037/0021-9010.92.1.228

Judge, T. A., Matocchio, J. J., \& Thoresen, C. J. (1997). Five-factor model of personality and employee absence. Journal of Applied Psychology, 82(5), 745-755. http://dx.doi.org/10.1037/0021-9010.82.5.745

Lau, C. M., \& Sholihin, M. (2005). Financial and nonfinancial performance measurement: How do they affect job satisfaction. The British Accounting Review, 37(4), 389-413. http://dx.doi.org/10.1016/j.bar.2005.06.002

Mount, M., Ilies, R., \& Johnson, E. (2006). Relationship of personality traits and counterproductive work behaviours: The mediating effects of job satisfaction. Personnel Psychology, 59(3), 591-622. http://dx.doi.org/10.1111/j.1744-6570.2006.00048.x

Omar, F., Halim, F. W., Zainah, A. Z., Farhadi, H., Nasir, R., \& Khairudin, R. (2011). Stress and job satisfaction as antecedents of workplace deviant behaviour. World Applied Sciences Journal, 12(Special Issue of Social and Psychological Sciences for Human Development), 46-51.

Robinson, S. L., \& Bennett, R. J. (1995). A typology of deviant workplace behaviour: A multidimensional scaling study. Academy of Management Journal, 38(2), 555-572.

Salgado, J. F. (2002). The Big Five personality dimensions and counterproductive behaviours. International Journal of Selection and Assessment, 10(1-2), 117-125. http://dx.doi.org/10.1111/1468-2389.00198

Saucier, G. (1994). Mini-Markers: A brief version of Goldberg's unipolar Big-Five markers. Journal of Personality Assessment, 63(3), 506-516. http://dx.doi.org/10.1207/s15327752jpa6303_8

Spector, P. E., \& Fox, S. (2005). A model of counterproductive work behaviour. In S. Fox \& P. E. Spector (Eds.), Counterproductive workplace behaviour: Investigations of actors and targets, (pp. 151-174). Washington, DC: APA.

Vardi, Y., \& Weitz, E. (2004). Misbehaviour in organizations: Theory, research, and management. Mahwah: Lawrence Erlbaum Associates. 